
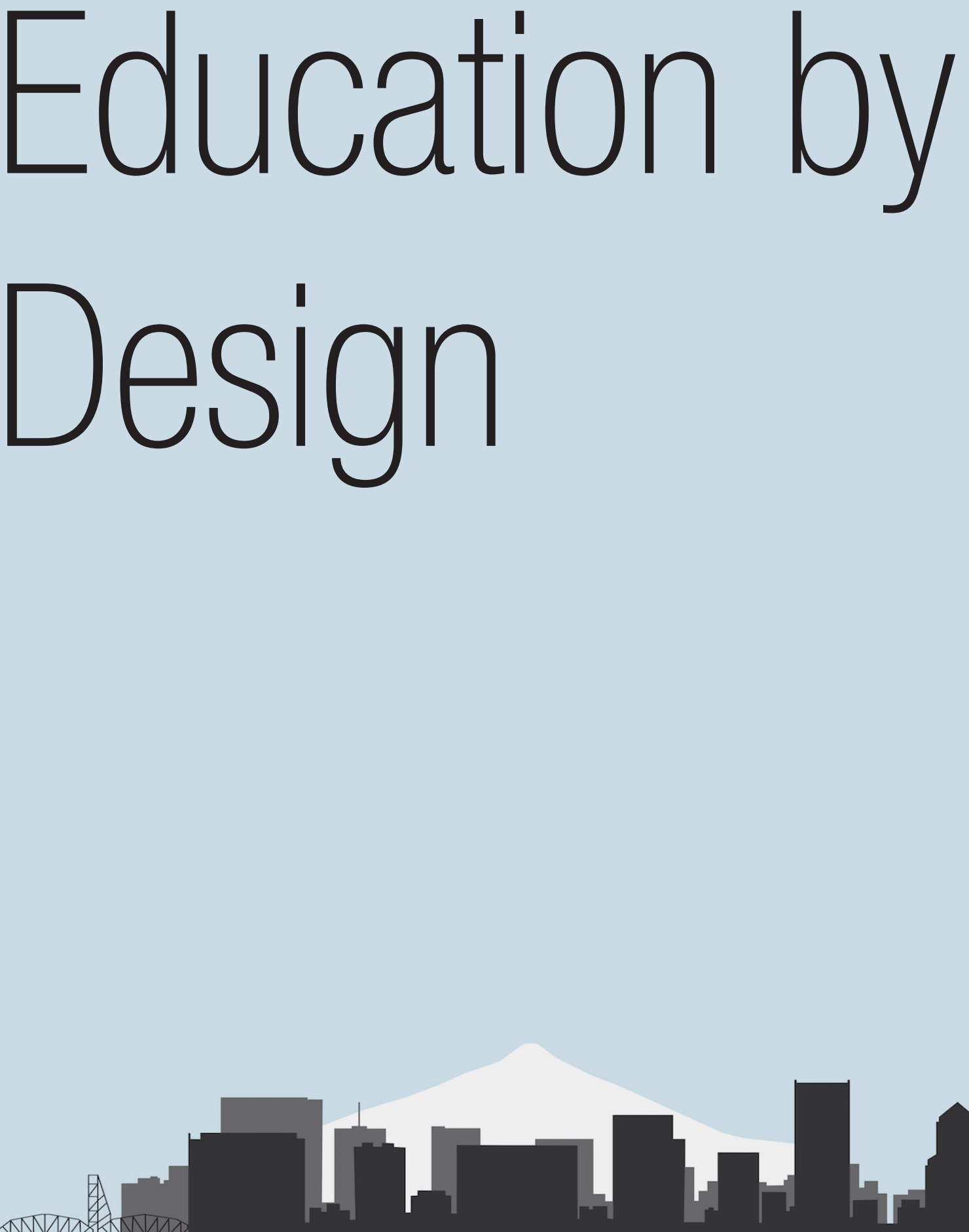

2019 Reynolds Symposium: Education by Design October 18-20, 2019 


\section{Organizing Committee:}

[co-organizers]

Professor Alison Kwok, Ph.D, FAIA, University of Oregon

Emeritus Professor John Reynolds, FAIA, University of Oregon

\section{[Symposium coordinator]}

Isabel Rivera, Ph.D., University of Oregon

Professor Walter Grondzik, P.E., Ball State University

Professor Bruce Haglund, AIA Assoc., University of Idaho

Assistant Professor Emily McGlohn, AIA, Auburn University

Associate Professor Ulrike Passe, lowa State University

Assistant Professor Siobhan Rockcastle, Ph.D., University of Oregon

Sharon Refvem, FAIA, LEED Fellow, Senior Associate and Director, Sustainability Resource Group, Hawley Peterson Snyder 


\title{
Design Integration: Lesson from a Research-Based Design Studio + Seminar
}

\author{
Robert B. Peña \\ Associate Professor \\ University of Washington \\ Seattle, Washington \\ rbpena@uw.edu
}

\author{
Chris Meek \\ Associate Professor \\ University of Washington \\ Seattle, Washington \\ cmeek@uw.edu
}

\begin{abstract}
Design Integration can be characterized as a working method that is iterative, continuously collaborative, and information-rich, and is targeted at optimizing the environmental, economic, and experiential performance of a building. Research, information, and application of digital methods that facilitate multivariate analysis are key components of design integration, a demonstrated process in professional practice for creating truly deep-green high-performance buildings such as Seattle's Bullitt Center.

Recognizing the potential for better integration between design and technology in the architecture curriculum at the University of Washington (UW), the Master of Architecture program is transitioning to a new curriculum model aimed at fostering greater collaboration, integration, and a research-based design methodology in design studios and across the curriculum. Underpinning this new curriculum is a greater commitment to research and to parametric analysis using computational methods as active components of the design studio process.

This paper reports on the third iteration of an academic and professional collaboration to develop, test and teach computational, performance-based design methods through a studio + seminar model. In each successive version of these courses, methods and technologies have been explored for teaching architecture students to create and document multivariate analysis and design synthesis workflows in an empirically-based design inquiry to develop design proposals for multi-story high performance buildings in downtown Seattle. Here we focus on our most recent studio + seminar course taught during the spring 2019 quarter.
\end{abstract}

\section{INTRODUCTION}

Contemporary architectural practice employs technology that allow the integration of complex data into the design process in real-time, the digital fabrication of building assemblies, and the representation and simulation of architectural experience through ever expanding computational means. Digital technologies that facilitate performance-based design generation and analysis are key components of design integration. As educators, our challenge is to teach the next generation of architects how to use these methods and understand how to deploy them most efficiently and effectively. The integration of empirical methods of science and technology with the intuitive synthetic process of art and design is a recurrent theme that is at the core of architectural practice and the education of architects.

To better teach this kind of $21^{\text {st }}$ Century, evidence-based design process, we needed to re-think both the structure and content of our largely $20^{\text {th }}$ Century curriculum model in the Master of Architecture program at the University of Washington. We started our discussions with two simple questions: what do we want to see in our students when they graduate from our programs; and, what can we do to facilitate their achieving this through both our teaching and the organization of our curriculum? After a wide-ranging discussion the consensus was that our curriculum should aim to develop highly motivated, creative, independent thinkers who value design as a critical contribution to society; and that our curriculum should cultivate an understanding of the place of research, technical knowledge, and broad social and humanistic knowledge in the realization of meaningful architectural design. 
We see the necessity of preparing students for a continually changing work environment in which architectural knowledge is understood and applied broadly to many different arenas related to the built environment. The curriculum should be structured to promote the development of research and design skills in students, and to facilitate innovative and creative teaching by faculty. Just as the workplace is in a state of constant change and renewal, so too should be the curriculum and teaching in our department.

\section{Curriculum Context}

The curriculum that grew from these discussions is structured to adapt to evolving challenges in the built environment and to accommodate emerging design technologies, tools and processes. This new curriculum structure will be fully implemented across all three years of the graduate program during the 2019-20 academic year. It is organized within the 3-year, nine-quarter program (plus summers) into five blocks, each with a particular set of objectives, illustrated in Figure 1. Each block has its own identity and role in constructing the whole of the program. They contain a progressive sequence of courses and experiences, each block supported by the knowledge and skills developed in the previous block(s).

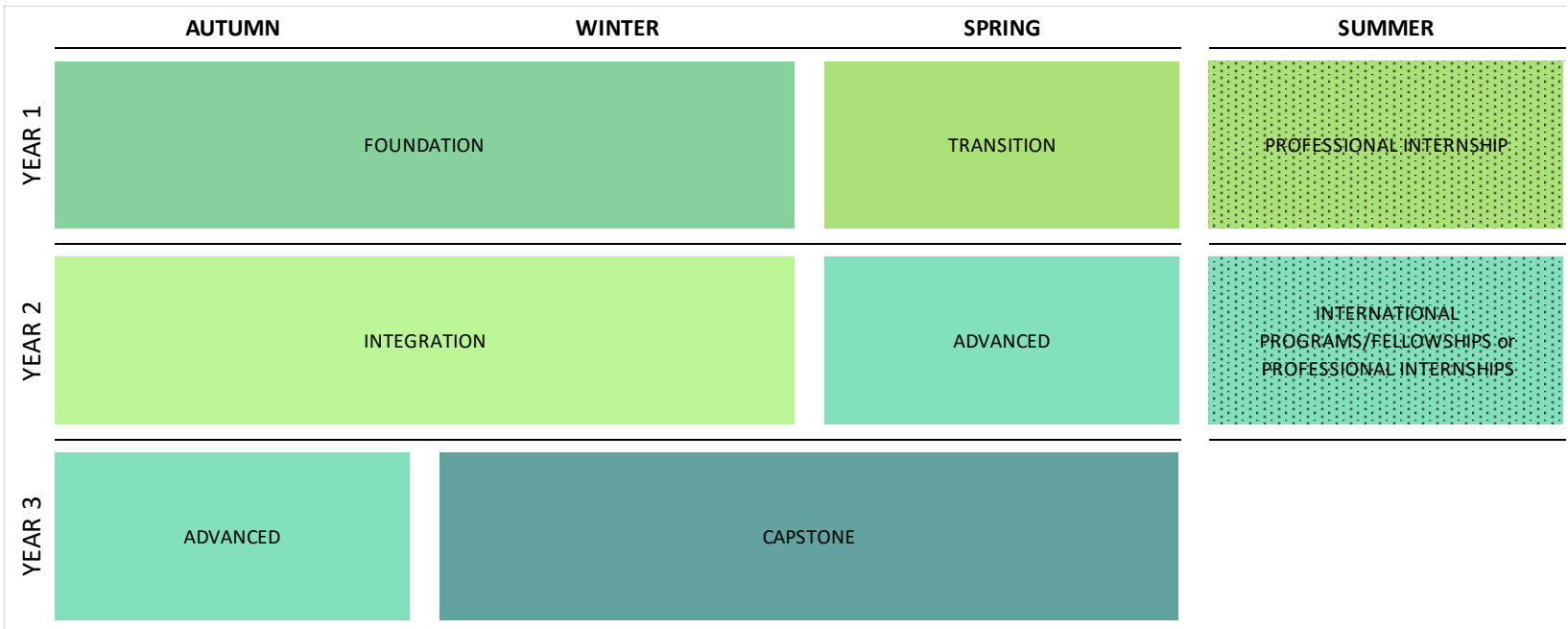

Figure 1. New UW Master of Architecture Curriculum Structure (2019-20)

The Foundation terms are instructed in a highly collaborative and coordinated manner, integrating content across disciplinary boundaries to support development of a strong, collaborative cadre among the entering graduate students. The Transition block is aimed at preparing students for a professional internship, made possible by the Department of Architecture's Professional Advisory Council (PAC), during the summer between the first and second year of the program. Year two begins with the Integration block, organized around 21st Century grand challenge themes of urbanization and climate change. The Advanced block makes more explicit the open-ended opportunities of a less structured curriculum with opportunities for special studios, foreign study, and college-wide collaborations. The culminating Capstone block contains the option of either a 2-term independent thesis, two research studios with linked research seminars, or potentially a single two-term research studio and linked seminar combination.

\section{Capstone Advanced Research Studios and Research Seminars}

After successfully completing a course in research methods and four studios, two Integration and two Advanced studios, students are eligible to enter the Capstone block which has two tracks: Advanced Research Studios + Seminar track or Independent Thesis track. The prerequisite Research Methods and Communication course introduces the students to current research methods. The combination of the Advanced Research Studio and Research Seminar allows them to refine and apply these research methods in the context of their design work. 
Starting winter term 2020, Advanced Research Studios will be offered in conjunction with Research Seminars, which support the research component of the studio by investigating current interdisciplinary topics in the built environment. This combination will encourage students to integrate rigorous, designrelated research with the design of a comprehensive studio project, with faculty support and instruction. These studios and seminars can be taught by the same faculty, by a faculty team, or by a team of faculty with professional partners. The studio component will focus on the development and representation of a comprehensive design project, while the parallel seminar will allow students to advance, document and illustrate related research.

\section{PERFORMANCE BASED DESIGN STUDIO + SEMINAR}

During the development of this new curriculum, a research studio model was explored through a number of advanced design studios having an explicit research component built-in to the studio course. These led organically to the idea of a research seminar plus a comprehensive design studio. This model was developed and tested over three years through a partnership between the Department of Architecture, the Integrated Design Lab, and Perkins+Will's Seattle and San Francisco offices. In these proof-of-concept courses, a research seminar was offered one term, followed by a comprehensive design studio the following term, where the results of the seminar were applied to the design project. The third iteration of this model occurred Winter and Spring terms, 2019.

\section{High Performance Building Seminar (Winter 2019)}

As in the two previous iterations, the design studio was preceded with a seminar during winter term. The subjects of this seminar were framed around a specific project under development in the Seattle office of Perkins+Will. In addition to addressing Seattle's requirements for affordable housing under the citywide Mandatory Housing Affordability (MHA) legislation known as HALA, the Housing Affordability and Livability Agenda, this project is also aimed at achieving high levels of environmental performance through compliance with Seattle's Living Building Pilot Program (LBPP). The LBPP is based on the Living Building Challenge ${ }^{\mathrm{TM}}$ (LBC), developed by the International Living Future Institute.

This seminar laid the groundwork for an advanced research design studio, and their development of design proposals for a mixed-use tower, by researching precedents, collecting design resources, problem definition, cost-comparables, and target setting. Perkins+Will provided their full analysis of the proposed site including information about existing conditions, zoning and code requirements, comparable revenue expectations, and anticipated construction costs.

This seminar was targeted at students entering the post-professional High-Performance Building program but was also open to students in the professional Master of Architecture and Master of Science in Design Computing programs, as well as students in allied engineering disciplines. The seminar was instructed through guest lectures, discussions, and directed investigations into specific topic areas. The research topic areas assigned to groups and individuals included opportunities and incentives, climate and site analysis, energy efficiency, renewable energy, rainwater and waste systems, construction costs and revenue comparables.

The seminar deliverables were assembled into a publication that described the objectives for the project and identified the key goals and metrics. It included guidance for a performance and evidence-based design and decision-making process, along with information and data pertaining to the proposed building type and location. The required project evaluation metrics are identified in Table 1.

Students presented an overview of their topic area, a detailed written report, and a shared folder with tools, resources, and data sets. They presented this material at the end of the seminar to a jury of practitioners, building owners, and developers for feedback; and again, to the students during the first week of the following quarter as part of the studio kick-off. 
Table 1. Required project evaluation metrics

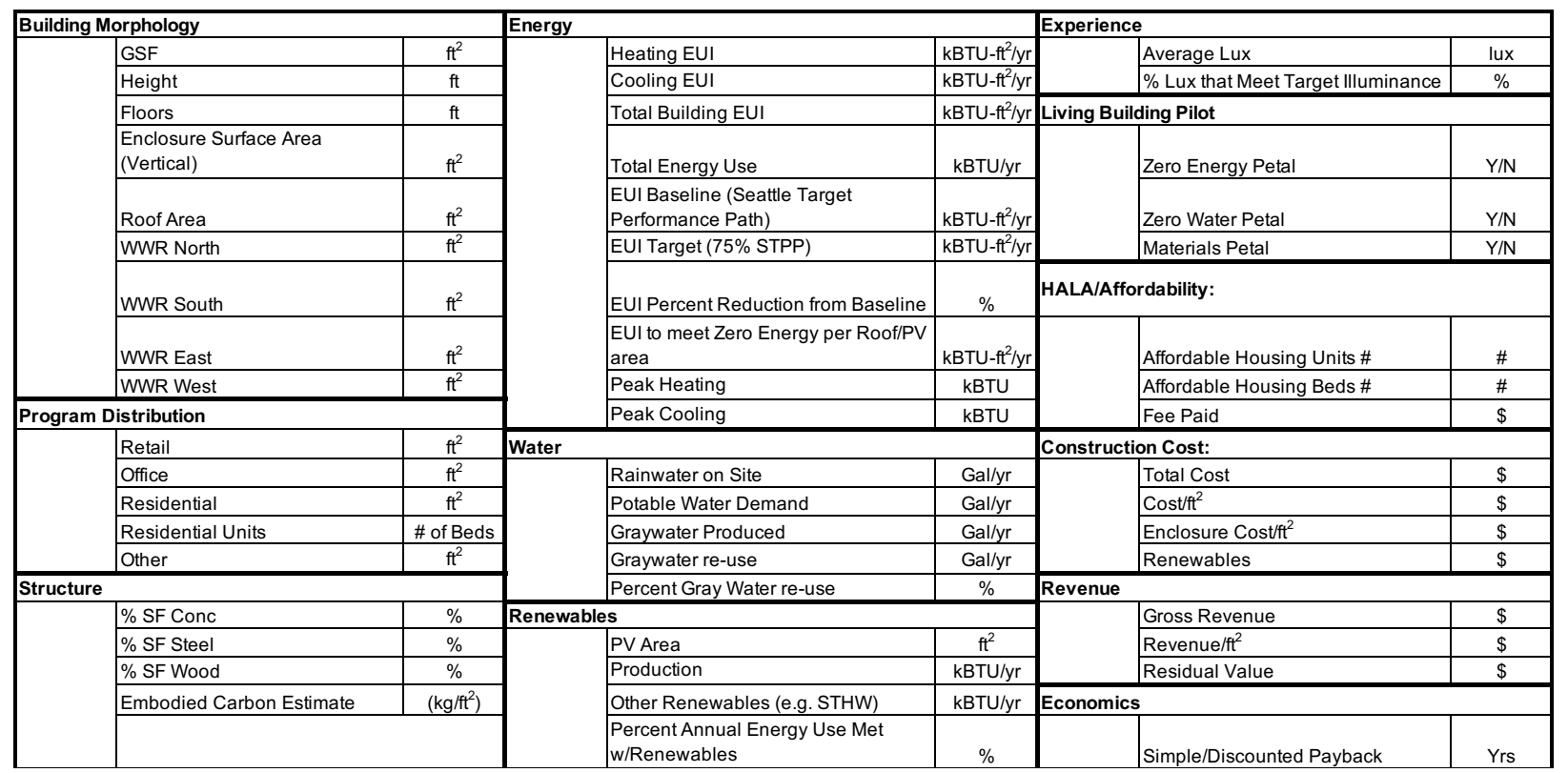

\section{Research Studio + Seminar (Spring 2019)}

A handful of the students from the research seminar joined the research studio the following term. This course was formulated with an aim toward integrating computational and performance-based thinking into the building design and representation processes. This faculty-led, team-instructed studio had active instructional support from members of Perkins + Will's Seattle and San Francisco offices, WSP (engineering services), and the University of Washington Integrated Design Lab. The approach adopted a hybrid consultant-designer model where experts in the field provided hands-on building performance simulation tools and problem formulation assistance but allowed the design teams to explore extensive alternatives at speed and scale without being encumbered by troubleshooting the tools themselves.

A companion seminar met twice a week between studio days and focused on problem formulation and design communication. The working proposition of the course is that a design proposal is an argument for a design solution to a problem, and that a compelling argument employs three dimensions to formulate a strong case: evidence, images, and a design narrative. Drawing on information from the previous research seminar, students used this venue to discuss and develop their argument, particularly their design narratives. Through a series of weekly writing assignments, the seminar was used to develop and refine the written, oral, and graphic components of their argument.

The overarching studio theme is to investigate and document project performance in attribute categories of economy, ecology, and experience; and to interweave empirically based evaluation with design synthesis based on value-weighted outcome goals. The design vehicle is a mixed-use tower on a viaductfree Seattle waterfront site. The owners of the " 75 Marion Square" site, who are currently working with Perkins+Will on conceptual development of a project on this site, served as critics of the student's design proposals.

Students developed proposals for a range of program mixes; however, they were limited in potential program use-types to office, retail, and multifamily residential since energy targets, revenue expectations, and construction costs for these space types are readily available on a unit or square-foot normalized basis for use in establishing project performance baselines and targets. 


\section{Project Definition}

Students were assigned a partner based on a survey of their skills and experience. Teams were given two weeks to develop concept-level building programs and preliminary massing diagrams for the 75 Marion Square site around the design parameters of experience, ecology and economy, and developed under the site's zoning guidelines, HALA and Seattle's LBPP. Using spreadsheet tools containing performance criteria for energy targets, revenue expectations, and construction costs, they developed a scheme that favored each of the three design parameters, and a fourth that optimized them along the values selected by each design team. Teams were free to modify the program mix (office/retail/residential) to maximize the building height and leasable area, number and type of dwelling units, sustainability, and qualitative concerns. They could also propose alternatives to the current zoning but were required to describe the exact code departures requested and provide a compelling rationale.

In graphic, tabular and written form, each team documented performance criteria for three concepts, each optimizing either experience, ecology or economy, and a fourth preferred option that offers the best overall value for the site by making the most of all attributes, as illustrated in Figure 2.

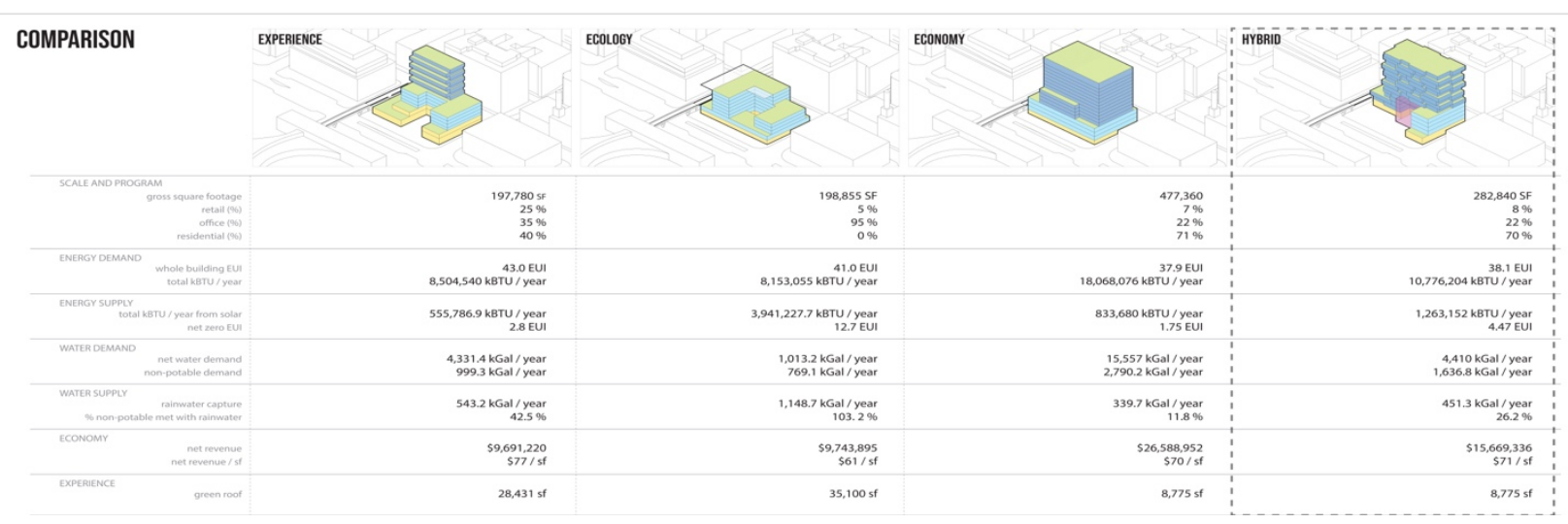

Figure 2. Project Definition summary (student team: Paige Collins and Benny Yeo)

Each concept's pro-forma contained a program component analysis benchmarking the typical operational energy and water loads, and embodied carbon, for each of the program elements, and an estimate of the square foot construction costs and annual net revenue by space type of each concept. They identified the compliance path(s) for each concept with Seattle's LBPP and the key metrics for achieving at least one of the three mandatory environmental criteria (energy, water or materials). They were also required to demonstrate the pathway for compliance with the Mandatory Housing Affordability (MHA) legislation of the City of Seattle's Housing Affordability and Livability Agenda (HALA). For each concept they described any incentives applied, their impact on the program, and an estimate of the scheme's economic performance. Teams were required to do a site resource analysis estimating the total site renewable energy and rainwater capture potential.

Teams were compelled to define what counts for the success of each concept proposal by identifying the key performance attributes organized in the three attribute categories: experience, ecology and economy. They included, but were not limited to the attributes of comfort, views, daylight, connection to nature, indoor air quality, productivity, energy use, water use, life cycle performance, longevity, maintenance, and embodied carbon. Where possible, teams were urged to reference existing standards to quantify their design proposal's potential performance against these outcome goals. While working quickly at a high level of concept development, teams were encouraged to begin thinking about strategies for sun control, daylighting, heating, cooling and ventilation.

At the end of the second week of studio, students presented their four concepts to the developer and members of the Perkins+Will design team for feedback. In seminar, they reflected on this feedback, discussed their positions, and analyzed their preferred options through the evidence from their initial analysis, informed by the values of each team member. 
In the two weeks that followed the first review, teams were charged with developing a single concept-level building design using the experience, ecology, economy framework to arrive at a concept to take forward into detailed analysis and development. The first of five workshops was used to launch development of their concept designs.

\section{Workshops}

The structure of the Seattle LBPP requires that each project achieve full compliance with one of the three most technically challenging dimensions (or "petals") of the Living Building Challenge ${ }^{\mathrm{TM}}$ (LBC): zero-net water, zero-net energy, or compliance with the Materials "Red-List" of prohibited materials and sourcing guidelines. These areas, plus a facade design exercise, were the focus of a sequence of weekly technical workshops. The structure of these workshops included a Monday guest-lecture and hands-on workshop, mid-week desk critiques and simulation assistance, and a Friday pin-up and review with practitioner subject-matter experts. During the Friday session students presented their own methods for representing performance data for key attributes of their project as well as case studies for information visualization.

Members of Perkins+Will's Research Lab instructed the first workshop on parametric design and simulation using the Design Space Construction (DSC) framework and methods for adapting them to the needs of their project. The workshop combined an introduction to the theory and hands-on experience with the visual programming-based parametric analysis scripts. This tool was used and adapted throughout the studio to quickly output performance data for design scenarios for comparative analysis. Students were provided with tutorials for how to apply the scripts to the high-rise context. Students had access to members of the Integrated Design Lab to assist with formulating and troubleshooting computational tools during studio hours. These resources were made available to enable the studio participants to focus on testing design alternatives and conducting synthesis activities rather than spending time in the mechanics of the quantification tools.

The second was a water workshop that was structured around three key outcome goals. First was to estimate the total annual gallons of harvestable rainwater falling on the building site area. Second was to identify the anticipated water use intensity and total consumption for each program component. Third, the student teams calculated the potential greywater production and consumption for each program type. This exercise allowed students to test-fit their project for achieving the LBC water criteria or "petal," and further to identify synergies between each program typology and potable water consumption, grey water production, and greywater recycling. With technical assistance from a building services engineer from the global engineering firm WSP, student teams developed water system flow diagrams. The LBC Water Petal requires meeting all water use through on-site captured rainwater; however, the Seattle LBPP requires that all non-potable water services (e.g. toilet flushing) are met with non-potable water. This requirement led several teams to size residential areas, which produce significantly more greywater than they can use, to optimally serve office areas, which require significant greywater for toilet flushing. At the end of week four students presented their concept designs along with their key project objectives and performance targets, and they identified the areas for focused development for the remainder of the term. At this point, program mix, and project objectives were solidified and the projects moved into a deeper level of concept design.

Following this mid-term review, the next workshop was on energy simulation and renewable energy. This workshop was built around identifying the key variables that drive building energy use intensity, peak heating and cooling loads, and opportunities for on-site renewable energy generation. Each team was expected to build a simplified massing model for thermal analysis in Rhino, link this geometry to grasshopper, and manipulate the scrip to test a range of scenarios to understand how choices either improve or diminish building energy performance. At this stage of design only architectural components such as glazing, massing, and program type were subject to modification. This isolated the energy-effects of architectural form decision-making which allowed students to see the interactive impacts of heating, cooling and lighting while seeing whether those changes had an overall positive, negative, or neutral impact on building energy consumption. 
Following the energy workshop, the façade development workshop was intended to synthesize energy concepts with goal-setting for daylighting, views, passive ventilation, and solar control. It was also intended to create a framework for shaping the geometry and location of windows, shading devices, and exterior spaces. This used both the Design Space Construction (DSC) parametric analysis tools and the quick facade evaluation tool COMFEN (Selkowitz, et al., 2011). Further, students identified facade case studies, cladding and detailing methods for potential material choices. These studies were targeted to "typical" components of the project such as an office floor and a residential floor and began to shape the visual character of the building enclosure.

At the end of week seven, teams presented their design concepts. They were asked to document their major decision-making process, their program development process, and their approach to the site zoning envelope and the Living Building Ordinance/HALA. They documented their water analysis, energy analysis, solar/renewables analysis, façade strategies and identified their key decision points. They presented the alternatives explored in either parallel coordinates plot form or other methods graphic representation to support the rationale for their current project development. The annotated section in Figure 3 illustrates one method of communicating the key design concepts.

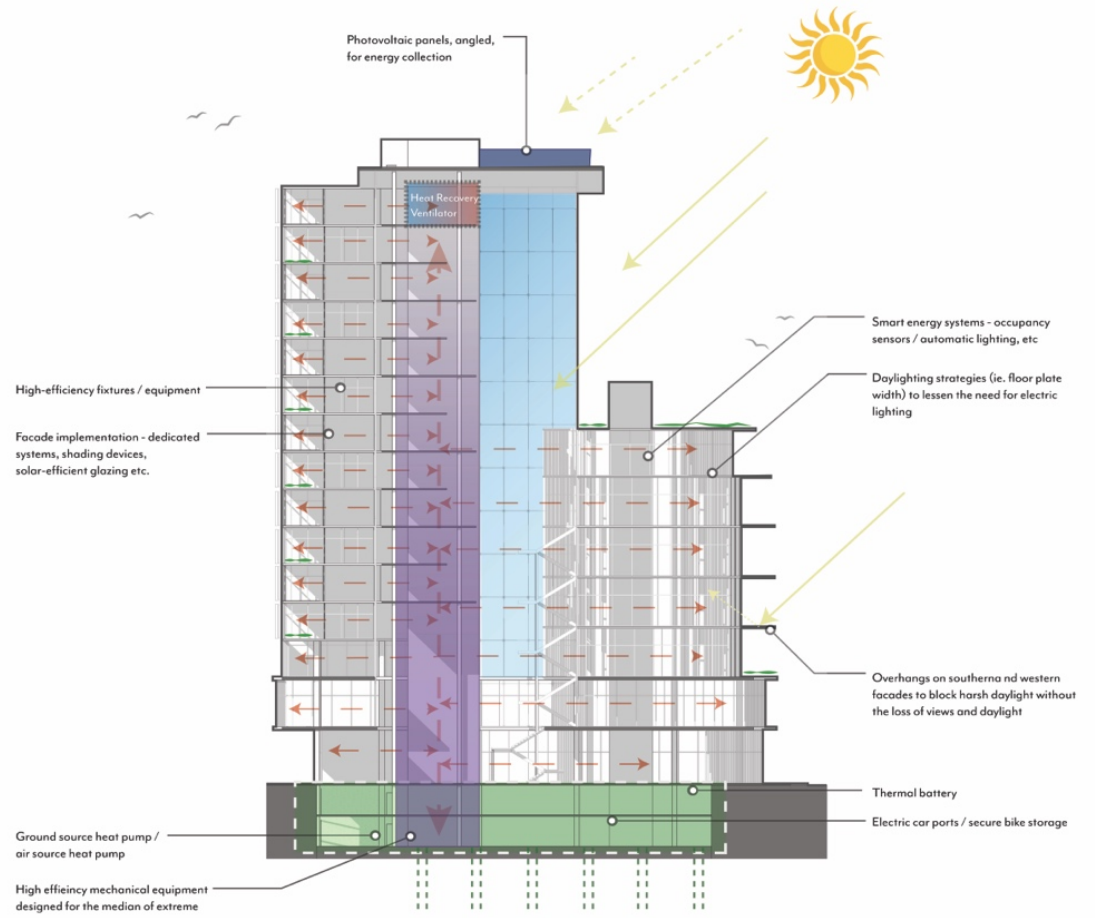

Figure 3. Annotated Systems and Concept Section (Maura Witzel)

\section{Synthesis and Innovation}

The final phase of the studio was aimed at synthesis and innovation. Students used this analysis process and information about performance in a creative synthesis process in which they explored the design spaces further and added new decisions.

Students were asked to document and illustrate their processes for evaluating spatial, material, and formal design decisions based on empirical multidisciplinary performance criteria. Particular emphasis included collaborative project development and communication. They were expected to clearly articulate their performance targets, document their design and evaluation process, and detail performance outcomes and decision-making via graphic and written form. Students were expected to provide highquality representations of their design and to show final design data that enabled comparison across schemes in terms of the multiple input and output parameters discussed above. 
Students presented their "design arguments" using slideshows that presented a narrative documentation of key decision-points, questions asked and answered, and evidence supporting those choices. They were also required to present printed boards that communicated the architectural form and experiential intent. Lastly, they were asked to reflect on the process and identify new areas of research and development that can improve the financial, environmental, and social impacts of future projects.
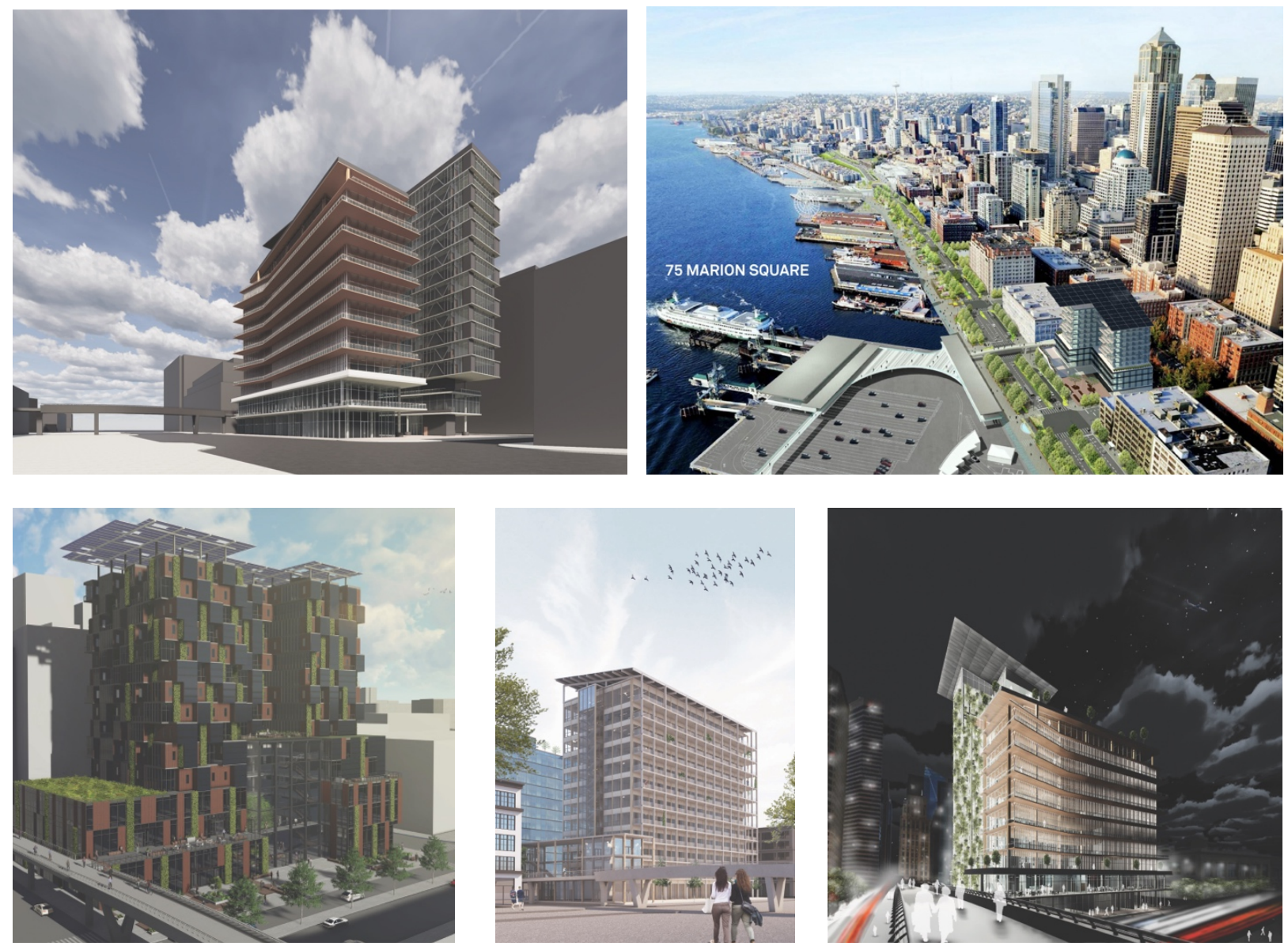

Figure 5. Student Project Renderings (clockwise from top: Maura Witzel; Aziz Alrumayyan \& Brian Dow; Paige Collins \& Benny Yeo, Nolan Higa \& Dan Lindau; Maura Witzel;)

\section{LESSONS AND OBSERVATIONS}

"An un-aimed arrow never misses." This maxim applies to many academic design studios where the proof is in the process and the measure of a project is largely in the eye of the author, defended against the opinions of outside reviewers. This research studio + seminar model is an altogether different proposition. It begins with a thoroughly researched evaluation of the physical, economic and regulatory constraints of the site, and the opportunities to optimize building performance using site resources. The design vehicle is assembled by each student team employing a strategic mix from three types of program possibilities - any defensible combination of office, retail and housing; and three primary evaluation criteria and their corollaries: economy, ecology, and experience.

Students are provided a digital toolkit for testing design alternatives against key performance criteria, they're organized into collaborative teams with expert consultants and outside professionals, they're tasked with finding the best possible design solution within the context of Seattle's Living Building Pilot Program, and they're required to defend their outcomes with evidence, images, and a clear design narrative. 
What has emerged through both intentional and organic development is a studio curriculum that operates in two parallel and interwoven tracks: (1) the creation of design spaces, querying models, and quantification of performance; and (2) the synthesis of that information into coherent architectural form. Teams that develop the ability to work in these two paths simultaneously seem to arrive at the most successful design outcomes.

Over the three iterations of this research studio + seminar model, different models have been used to deliver specific subject-based information and design methodology for addressing energy, water, materials, building envelope, etc. We've concluded that a more prescriptive set of workshops and activities results in better outcomes that allowing students more space to develop their own pathways. The most successful balance of workshops and application was actually achieved the first year; we didn't need to reinvent this wheel in the following iterations.

This studio challenged us to balance the broad, exploratory nature of design studio with the research objective of uncovering repeatable, actionable knowledge that is broadly implementable. We sought higher-level "research outcomes," any clear take-aways such as innovative massing schemes or specific ideas that could be translated and broadly shared to inform other designers seeking to meet the studio objectives. To try to derive such outcomes, during the second year of the studio we created a broader suite of metrics (Table 1, page 4) that all students were required to track through the project so that the faculty and the researchers at Perkins + Will could deduce commonalities among the most successful projects, or identify patterns and themes that were universal to the studio effort. We were hoping for some larger lessons to come out of the students' innovative project-by-project work, but these broad lessons but these never really emerged.

Perhaps we're not looking at it in the right way to generate clear "take-aways," or perhaps we're allowing for too much self-direction in establishing project goals. This is a double-edged sword in that having some individuality and variety in objectives make the studio more interesting, the conversations richer, and the studio more exploratory, but the results are less the repeatable outcomes of a research project. This subject will inform discussions with our colleagues who are assembling the first round of research studio to be offered during winter term 2020.

The compressed timeframe of a 10-week quarter, students didn't have time to master most of the digital tools employed, so we hired facilitators (advanced students and a research assistant from the Integrated Design Lab), to provide technical support. This consultant model parallels the use of consulting services in professional practice. This service allowed the students to think more about the design questions the tools were answering rather than focusing on the tools themselves. The aim was to free-up the students to use the results from their digital modeling and parametric analysis in a more synthetic manner to achieve the intended design outcomes.

We received a range of feedback from students, from those that enjoyed the quick pace and the broad scope of parameters, to others that felt like they were drinking from a firehose. To address this, we hired facilitators (advanced students and a research assistant from the Integrated Design Lab), to provide technical support. This consultant model parallels the use of consulting services in professional practice. This service allowed the students to think more about the design questions the tools were answering rather than focusing on the tools themselves. We believe that this freed the students to use the results from their digital modeling and parametric analysis in a more synthetic manner to achieve the intended design outcomes.

For those overwhelmed by the pace and scope of new design parameters, the biggest challenge was trying to address multiple criteria simultaneously using a variety of tools and methods. They would have preferred focusing on in a single subject area at a time (e.g. potable water supply), rather than multiple subjects simultaneously (water supply, wastewater, renewable energy production, etc.). Finding opportunities for synergies between systems is central to the idea of design integration, to this issue may be inherent, but having more than one, ten-week term, would provide a more comfortable pace. 
Students noted that the contributions from outside professionals who instructed some of the workshops, provided design consultations, and provided insightful design critique, was deeply appreciated. The studio has benefitted tremendously from the generous support of Perkins+Will and the Seattle design community over the three iterations of this model. They also noted that the exposure to a wide range of tools from Rhino plug-ins and scrips (Grasshopper, Ladybug, etc.), spreadsheets, and open source tools such as COMFEN, was valuable and informative. Several students noted that after each of the three major reviews they were compelled to revise and refine their design narrative, and that having the seminar to both write and talk-through these revisions was very helpful.

From our own experience and feedback from students, it's clear that 10 weeks is not enough time to develop the holistic process of evidence-based design we hope to achieve in this advanced, comprehensive design studio. Our new curriculum structure will allow for either one- or two-term "research studios" in the final Capstone block of the graduate program. In this two-term version, the first term seminar would conduct research and document outcomes as a design reference, similar to the seminar that preceded this studio. The second seminar would focus design communication, offering a venue to test, revise and refine a "design argument" in written and graphic form, much like the seminar that was concurrent with the most recent iteration of this studio.

The recurrent theme at the core of architectural practice and design education: the integration of empirical methods of science and technology with the intuitive synthetic process of art and design, has guided the development of this studio model. Helping students develop the ability to operate simultaneously in both realms is the objective of the next iterations of the evidence-based design research studio/seminar.

\section{ACKNOWLEDGEMENTS}

We would like to thank members of the Integrated Design Lab: Heather Burpee, Michael Gilbride, Andrew Gustin; Perkins+Will: John Haymaker, Devin Kleiner, Marcelo Bernal, Kay Kornovich, Erik Mott, Carsten Stinn, and the Research Board at Perkins+Will for their participation and support of this work; our design consultants: Charles Gronet and Tom Marseilles (WSP); the owners and developers of the 75 Marion Square project: Jordan and Martin Selig; and the students of this design studio + seminar: Aziz Alrumayyan, Madison Brachvogel, Paige Collins, Brian Dow, Gayle Elam, Nolan Higa, Dan Lindau, Kelsey McKay, Steven Moehring, Nishat Tasnim, Morgan Warner, Maura Witzel, Benny Yeo.

\section{REFERENCES}

Haymaker, J. and Perkins+Will, (2018) “Design Space Construction,” 01-Feb-2015. [Online]. Available: http://designspaceconstruction.org. [Accessed: 04-Aug-2018].

Haymaker, J., Meek, C., Kleiner, D., Pena, R., Burpee, H., Norwood, W., "Constructing PerformanceBased Tools and Practitioners for Exploring Living, Mixed-Use, High-Rise Building Design Spaces, ”Perkins+Will Research Journal. 18 December 2018

International Living Future Institute (ILFI) (2018), International Living Future Institute. [Online]. Available: https://living-future.org/. [Accessed: 16-Aug-2018].

Selkowitz, S., Mitchell, R., McClintock, M., McQuillen, D., McNeil, A., Yazdanian, M., (2011), COMFEN 3.0 - Evolution of an Early Design Tool for Commercial Facades and Fenestration Systems. - Report Number: LBNL-5179E

City of Seattle (WA, USA), (2018) Department of Construction and Inspections (SDCI), Seattle Living Building Pilot Program. http://www.seattle.gov/dpd/permits/greenbuildingincentives/livingbuildingpilot/, Retrieved September 2018 